\title{
Panamanian biodiversity: a valuable source of novel lead compounds of economic and medical potential
}

\section{Opinion}

The rich plant diversity of developing countries in globalization era is a reservoir of unexplored sources of drugs and aromatic plants. Despite the intensive investigation of terrestrial flora, it is estimated that only $6 \%$ of the approximately 300,000 species (some estimates are as high as 500,000 species) of higher plants have been systematically investigated pharmacologically, and only some $15 \%$ phytochemically. ${ }^{1}$ The endophytic microorganisms that reside between living plant cells have received little attention. Historically, natural products have provided an endless source of medicines, and despite reduced funding for natural products-based drug discovery, natural products remain an undiminished source of new pharmaceuticals. Even though industrial funding specifically allocated for natural product based drug discovery declined from 1984 to 2003, the percentage of natural-products derived, small-molecule patents has remained relatively unchanged. A comprehensive review of human drugs introduced between 1981 and June 2006 suggests that, out of 1010 NCEs, 43 (4.3\%) were unaltered natural products, and a further were derived from natural products (usually by semi synthesis) and the remaining 735 were synthetic molecules. However, 262 of the synthetic molecules had a natural-products derived pharmacophore or could be considered natural products analogs.

Medicinal plants remain an important source of new drugs, new drug leads, and New Chemical Entities (NCEs). Of 132 drugs approved by the FDA from 2008-2012, approximately 30\% were of natural origin. The contribution of natural products to new NCEs of natural origin remains robust and is perhaps less appreciated Overall $25 \%$ to $40 \%$ of all NCEs of natural origin are derived from natural products. ${ }^{2}$ Ever increasing demand for botanical products is a global tendency and it is estimated that in 2015 this figure reached US \$107 billions. In the United States, the sale of herbal supplements in 2017 increased to US $\$ 7$ billion. If we consider nutraceutical supplements this figure is even higher. There are over 500 INDs (Investigational New Drugs) at FDA for botanical drugs in different stage of development. The first drug based on green tea Veregen ${ }^{\circledR}$ was approved in 2008 for the treatment of genital warts. In Brazil, Acheflan ${ }^{\circledR}$ was the first plantbased topical anti-inflammatory drug approved.

Panama is a unique terrestrial bridge of great biological importance. It is considered a biodiversity "hot spot" in the word and occupies $4^{\text {th }}$ place among 25 most plant rich countries in the Americas, with $13.4 \%$ endemism. Over the last four decades, we have prepared ethnobotanical inventories of Gunas (formaly called Kuna), NgäbeBuglé (formaly called Guaymies) and Naso (Teribe) Amerindians and have an ethno medical uses Database "PlanMedia," (CIFLORPAN) with entries from South and Central America. These inventories have served us in selecting plants for further chemical and pharmacological investigations. Another important area has been the study of aromatic flora of Panama, and so far we have studied 40 plants of Myrtaceae and Piperaceae family, some of the essential oils exhibit activities against Helicobacter pylori and Aedes Aegypti. ${ }^{3}$
Volume 6 Issue 2 - 2018

\author{
Mahabir P Gupta \\ School of Pharmacy, University of Panama, Panama
}

Correspondence: Mahabir P Gupta, Center for Pharmacognostic study of Panamanian Flora, School of Pharmacy, University of Panama,Apartado 0824-00172, Panama, Republic of Panama, Email mahabirpgupta@gmail.com

Received: March 15, 2018 | Published: April 04, 2018

Bioassay guided fractionation of active extracts from a library of 26,061 extracts in various biochemical targets have allowed us to obtain 194 new compounds, of which 174 were active. ${ }^{4}$ Some 345 known compounds were isolated for the first time from Panamanian plants. In a multinational project AgroCos of European Union (FP7 Framework Program) we identified compounds for agricultural (fungicides and herbicides) and for cosmetics (anti-aging) uses. A chemoinformatic analysis of natural products of Panama, showed that natural products isolated from Panamanian flora have great potential as a computational hit, since it has 184 molecular scaffods indicating a great structural diversity. In summary, Panamanian flora still remains and untapped source of useful compounds which may become phytomedicines.

\section{Acknowledgement}

Thanks are due to SENACYT, Panama for the SNI Distinguished Scientist award.

\section{Conflict of interest}

None.

\section{References}

1. Caballero GC, Gupta MP. A Quarter century of Pharmacognostic research on Panamanian flora: A review. Planta Med. 2011;77(11):1189-1202.

2. Santana AI, Vila R, Canigueral S, et al. Chemical Composition and biological activity of essential oils from different species of piper from Panama. Planta Med. 2016;82(11-12):986-991.

3. Guldbrandsen N, De Mieri M, Gupta M, et al. Screening of Panamanian Plant Extracts for pesticidal properties and HPLC- based identification of active compounds. Sci Pharm. 2014;83(2):353-367.

4. Olmedo DA, Gonzalez Medina M, Gupta MP, et al. Cheminformatic characterization of natural products from Panama. Mol Divers. 2017;21(4):779-789.

5. Tao L, Feng Z, Qin C, et al. Nature's Contribution to today's Pharmacopoeia. Nature Biotechnology. 2014;32(10):979-980. 